\title{
PENGARUH PRAKTIK KERJA LAPANGAN DAN PRESTASI BELAJAR TERHADAP KESIAPAN MEMASUKI DUNIA KERJA PADA SISWA KELAS XI PROGRAM KEAHLIAN TEKNIK GAMBAR BANGUNAN SMK N 5 SURAKARTA TAHUN PELAJARAN 2016/2017
}

\author{
Lilis Suryati $^{1}$, Rima Sri Agustin ${ }^{2}$, Taufiq Lilo Adi Sucipto ${ }^{3}$ \\ Email: suryatililis4@gmail.com
}

\begin{abstract}
Abstrak: Penelitian ini bertujuan untuk mengetahui (1) pengaruh praktik kerja lapangan terhadap kesiapan memasuki dunia kerja; (2) pengaruh prestasi belajar terhadap kesiapan memasuki dunia kerja; dan (3) pengaruh pengalaman praktik kerja lapangan dan prestasi belajar terhadap kesiapan memasuki dunia kerja.Populasi dalam penelitian ini adalah siswa kelas XI TGB SMK Negeri 5 Surakarta, dengan teknik pengambilan sampel yaitu total sampling. Penelitian yang digunakan adalah jenis penelitian Ex Post Facto, metode yang digunakan adalah metode deskriptif, dan menggunakan pendekatan kuantitatif. Pengumpulan data menggunakan angket dan dokumentasi. Teknik analisis data menggunakan analisis regresi ganda, namun sebelumnya dilakukan pengujian prasyarat meliputi : uji normalitas, uji linieritas, dan uji multikolinearitas.Hasil penelitian ini adalah, (1) terdapat pengaruh yang positif dan signifikan praktik kerja lapangan terhadap kesiapan memasuki dunia kerja, dilihat dari nilai koef. regresi X1 sebesar 0,549, nilai signifikansi sebesar $0,000<0,05$, dan nilai $t_{\text {hitung }}$ sebesar 6,913 $>t_{\text {tabel }} 2,045$. (2) tidak terdapat pengaruh yang signifikan prestasi belajar terhadap kesiapan memasuki dunia kerja, dilihat dari nilai koef. regresi X2 sebesar 0,640 , nilai signifikansi sebesar 0,290 $>0,05$, dan nilai $t_{\text {hitung }}$ sebesar 1,078 $<t_{\text {tabel }} 2,045$. (3) terdapat pengaruh yang positif dan signifikan praktik kerja lapangan dan prestasi belajar terhadap kesiapan memasuki dunia kerja nilai $\mathrm{F}_{\text {hitung }}=26,341$ sedangkan dari $F_{\text {tabel }}$ adalah 3,32. Sehingga $F_{\text {hitung }}>F_{\text {tabel }}$ dan nilai sig. $=0,000<0,05$. Kesiapan memasuki dunia kerja dipengaruhi oleh praktik kerja lapangan dan prestasi belajar sebesar $64,5 \%$. Secara parsial pengaruh praktik kerja lapangan terhadap kesiapan memasuki dunia kerja sebesar $61,146 \%$ dan prestasi belajar terhadap kesiapan memasuki dunia kerja sebesar 3,354\%

Kata Kunci : Praktik Kerja Lapangan, Prestasi Belajar, dan Kesiapan Memasuki Dunia Kerja
\end{abstract}

Abstract: This study aims to determine (1) the effect of fieldwork on the readiness to enter the world of work; (2) the influence of learning achievement on the readiness to enter the work world; And (3) the impact of fieldwork experience and

\footnotetext{
${ }^{1}$ Mahasiswa Pendidikan Teknik Bangunan Fakultas Keguruan dan Ilmu Pendidikan

${ }^{2}$ Pengajar Pendidikan Teknik Bangunan Fakultas Keguruan dan Ilmu Pendidikan

${ }^{3}$ Pengajar Pendidikan Teknik Bangunan Fakultas Keguruan dan Ilmu Pendidikan
} 
learning achievement on the readiness to enter the workforce.The population in this study were students of class XI TGB SMK Negeri 5 Surakarta, with sampling technique that is total sampling. The research used is Ex Post Facto research type, the method used is descriptive method, and using quantitative approach. Data collection using questionnaires and documentation. The data analysis technique used multiple regression analysis, but previously conducted prerequisite test include: normality test, linearity test, and multicolinearity test.The results of this study are (1) there is a positive and significant effect of field work on the readiness to enter the work world, seen from the coef value. Regression X1 of 0.549, significance value of 0,000 <0.05, and the value of $t$ count of 6.913> ttable 2.045. (2) there is no influence of learning achievement on the readiness to enter the work world but the variable is positive, seen from the coef value. X2 regression of 0.640, significance value of $0.290>0.05$, and the value of tcount of $1.078<$ ttabel 2.045. (3) there is a positive and significant influence of field work and learning achievement on the readiness to enter the work world value Fcount $=26,341$ while from Ftabel is 3.32. So Fcount $>$ Ftable and sig value. $=0,000<0.05$. Readiness to enter the world of work is influenced by the experience of field work practice and achievement of $64.5 \%$. Partially, the influence of field work on the readiness to enter the workforce of $61.146 \%$ and learning achievement of the readiness to enter the workforce of $3.354 \%$

Keywords: Field Work Practice, Learning Achievement, and Readiness Entering the World of Work

\section{PENDAHULUAN}

Adanya SMK merupakan bentuk upaya pemerintah dalam menghasilkan lulusan yang siap kerja. Sekolah Menengah Kejuruan (SMK) sendiri menganut Pendidikan Sistem Ganda (PSG). Pendidikan Sistem Ganda itu sendiri merupakan bentuk penyelenggaraan pendidikan keahlian profesional yang menyinkronkan antara pendidikan di sekolah dengan pendidikan di industri yaitu berupa praktik kerja lapangan atau praktik industri.
Tujuan dari praktik kerja lapangan agar siswa mendapat pengalaman kerja secara langsung di dunia kerja yang sesunguhnya.

Implementasi dari Pendidkan Sistem Ganda (PSG) di SMK N 5 Surakarta yaitu dengan adanya Praktik Kerja Lapangan yang wajib ditempuh siswa pada kelas XI semester IV dengan tujuan untuk mencari pengalaman kerja dan untuk beradaptasi dengan dunia kerja sebelum terjun langsung ke dunia kerja yang sesungguhnya. 
Walaupun semua siswa di SMK N 5

Surakarta sudah mendapatkan pengalaman praktik kerja lapangan yang apabila secara teori seharusnya sudah siap kerja setelah lulus, namun hal tersebut tidak berlaku pada dua siswa kelas XI TGB yang peneliti wawancarai, mereka mengaku belum siap kerja.

Berdasarkan hasil wawancara tersebut, peneliti ingin mengetahui apakah semua siswa kelas XI TGB juga sependapat atau tidak dengan dua siswa yang peneliti wawancarai. Banyak nya faktor yang mempengaruhi kesiapan memasuki dunia kerja, ditambah karena keterbatasan waktu, dana, dan pikiran, membuat peneliti mengerucutkan untuk meneliti dua faktor yang mempengaruhi kesiapan kerja, yaitu pengalaman praktik kerja lapangan dan prestasi belajar siswa. Selain itu dua faktor tersebut merupakan faktor yang terpenting dalam memasuki dunia kerja.

Menurut Hamalik (2007:21), praktik industri atau dibeberapa sekolah disebut dengan On The Job Training (OJT) merupakan modal pelatihan yang di selenggarakan di lapangan, bertujuan untuk memberikan kecakapan yang diperlukan dalam pekerjaan tertentu sesuai dengan tuntutan kemampuan bagi pekerjaan.

Menurut Djojonegoro (1998:79), praktik industri (PI) adalah bentuk penyelenggaraan pendidikan keahlian kejuruan yang memadukan secara sistematik dan sinkron program pendidikan di sekolah dan program penguasan keahlian yang diperoleh melalui bekerja langsung di dunia usaha atau dunia industri (DU/DI), secara terarah untuk mencapai suatu tingkat keahlian profesional. Tujuan Praktik Industri menurut Djojonegoro (1998:79) antara lain:

a) Menghasilkan tenaga kerja yang memiliki keahlian professional yaitu tenaga kerja yang memiliki tingkat pengetahuan, keterampilan, dan etos kerja yang sesuai dengan tuntunan dunia kerja.

b) Meningkatkan dan memperkokoh keterkaitan dan kesepakatan (link and match) antara lembaga pendidikan dan pelatihan kejuruan. 
c) Meningkatkan

efisiensi

penyelenggaraan pendidikan dan pelatihan kerja yang berkualitas professional dengan memanfaatkan sumberdaya pelatihan yang ada di dunia kerja.

d) Memberi pengakuan dan penghargaan terhadap pengalaman kerja sebagai bagian dari proses pendidikan.

Hal ini sesuai dengan tujuan pelaksanaan PKL di SMKN 5 Surakarta.

Menurut Tirtonegoro (2001 : 43), mengemukakan bahwa : prestasi belajar adalah penilaian hasil usaha kegiatan belajar yang dinyatakan dalam bentuk simbol angka, huruf maupun kalimat yang dapat mencerminkan hasil yang sudah dicapai oleh setiap anak didik dalam periode tertentu. Menurut Sudjana (2009), Suatu aktifitas dapat dikatakan atau dikategorikan hasil belajar apabila memenuhi unsurunsur sebagai berikut :

1) Adanya perubahan tingkah laku

2) Perubahan terjadi dari hasil latihan atau pengalaman

3) Perubahan itu menyangkut beberapa aspek, yaitu aspek kognitif, afektif, dan psikomotorik

Perubahan dari aspek kognitif, afektif, dan psikomotorik sudah didapat siswa kelas XI TGB dari pelaksanaan PKL dan teori pembelajaran di kelas, sebagai bekal untuk memasuki dunia kerja. Menurut Fitriyanto (2006 : 9), secara sederhana kesiapan kerja dapat diartikan sebagai suatu kondisi yang menunjukan adanya keserasian antara kematangan fisik, mental, serta pengalaman sehingga individu mempunyai kemampuan untuk melaksanakan suatu kegiatan tertentu dalam hubungannya dengan pekerjaan atau kegiatan. Menurut Slameto (2010: 113), faktor-faktor yang mempengaruhi kesiapan mencakup tiga aspek, yaitu: (1)Kondisi fisik, mental dan emosional,

Kebutuhan-kebutuhan, motif dan tujuan, (3) Keterampilan, pengetahuan dan pengertian lain yang telah dipelajari.

Berdasarkan pendapat di atas dapat disimpulkan bahwa praktik kerja lapangan atau praktik industri 
dan prestasi belajar merupakan faktor penting yang mempengaruhi kesiapan memasuki dunia kerja.

\section{METODE PENELITIAN}

Penelitian ini dilaksanakan di SMK Negeri 5 Surakarta yang beralamatkan di Jln LU. Adi Sucipto no. 42 Surakarta, Telp 0271-713916, Fax.0271-727068, Kode Pos 57143. Waktu pelaksanaan penelitian dilakukan mulai bulan Januari 2017 sampai bulan Agustus 2017. Subjek penelitian ini adalah siswa kelas XI TGB SMK Negeri 5 Surakarta tahun pelajaran 2016/2017 yang terdiri dari 32 siswa.

Teknik pengumpulan data yang digunakan berupa dokumentasi pengajaran disekolah berupa laporan hasil belajar (Rapor) siswa khususnya pada nilai menggambar dengan perangkat lunak (CAD) pada siswa kelas XI TGB SMK Negeri 5 Surakarta Tahun Pelajaran 2016/2017 semester III. dan kuesioner untuk memperoleh data untuk variabel pengalaman praktik kerja lapangan dan variabel kesiapan memasuki dunia kerja pada siswa kelas XI TGB SMK Negeri 5
Surakarta Tahun Pelajaran 2016/2017.

Uji validitas pada penelitian ini menggunakan uji validitas konstruk. Uji reliabilitas digunakan untuk menguji hasil pengukuran questioner yang erat hubungannya dengan masalah kepercayaan. Suatu alat tes dikatakan mempunyai taraf kepercayaan jika tes tersebut memberikan hasil yang tepat (ajeg).

Teknik analisis data yang digunakan dalam penelitian ini adalah analisis regresi ganda, sebelumnya terlebih dahulu melakukan uji prasyarat data menggunakan uji normalitas, uji linieritas, dan uji multikolinearitas.

Pengujian hipotesis dalam penelitian ini menggunakan analisis regresi ganda. Hipotesis ini adalah hipotesis yang menunjukan hubungan ganda sehingga untuk menguji hipotesis III digunakan teknik analisis regresi ganda, yaitu untuk mengetahui pengaruh antara kedua variabel bebas (X1 dan X2) secara bersama-sama terhadap variabel terikat (Y). pada uji ini menggunakan bantuan program SPSS versi 20. Hasil perhitungan 
kemudian dikonsultasikan dengan $F_{\text {tabel }}$ sehingga akan disimpulkan sebagai berikut :

1) $F_{\text {hitung }}>f_{\text {tabel, }}$ maka Ha diterima yang berarti ada pengaruh yang positif dan signifikan antara variabel XI dengan X2 terhadap variabel Y.

2) $F_{\text {hitung }}<F_{\text {tabel, }}$ maka Ha ditolak yang berarti tidak ada pengaruh yang positif dan signifikan antara variabel XI dengan X2 terhadap variabel Y.

Koefisien regresi dinyatakan signifikan apabila pvalue $<0,05$. Model persamaan regresi sebagai berikut :

$\mathrm{Y}=a+b_{1} X_{1}+b_{2} X_{2}$

Keterangan :

$$
\begin{array}{ll}
\mathrm{Y} & =\text { Kriteria } \\
\mathrm{b} 1 & =\text { Koefisien prediktor } 1 \\
\mathrm{~b} 2 & =\text { Koefisien prediktor } 2 \\
\mathrm{a} & =\text { Bilangan konstanta }
\end{array}
$$

\section{HASIL PENELITIAN DAN}

\section{PEMBAHASAN}

\section{Deskripsi Data}

Data - data yang diperlukan dalam penelitian ini diperoleh melalui angket (kuesioner) yang telah di uji oleh ahli dan di uji cobakan langsung pada siswa kelas XII TGB SMK N 2 Surakarta, kemudian di uji validitas dan reliabilitasnya.

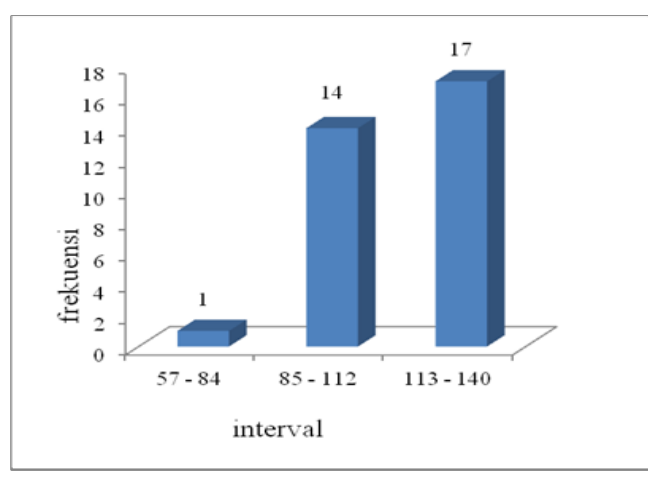

Gambar 1. Data Praktik Kerja Lapangan

Berdasarkan gambar 1 bahwa sebanyak 17 responden rata-rata menjawab sangat setuju pada angket penelitian. Kemudian sebanyak 14 responden rata-rata menjawab setuju pada angket penelitian, dan terendah sebanyak 1 responden menjawab ragu-ragu pada angket penelitian.

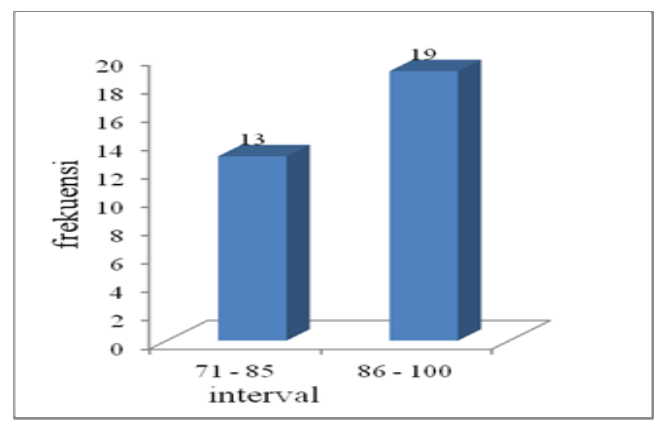

Gambar 2. Data Prestasi Belajar Berdasarkan gambar 2 bahwa, sebanyak 19 responden mendapat nilai dengan kriteria sangat 
baik. Kemudian sebanyak 13

responden mendapat nilai dengan kriteria baik. Hal ini berarti responden yang memperoleh skor prestasi diatas rata-rata yaitu sebanyak 19 responden dan yang memperoleh prestasi dibawah ratarata yaitu sebanyak 13 responden, sehingga memiliki prestasi belajar diatas rata-rata.

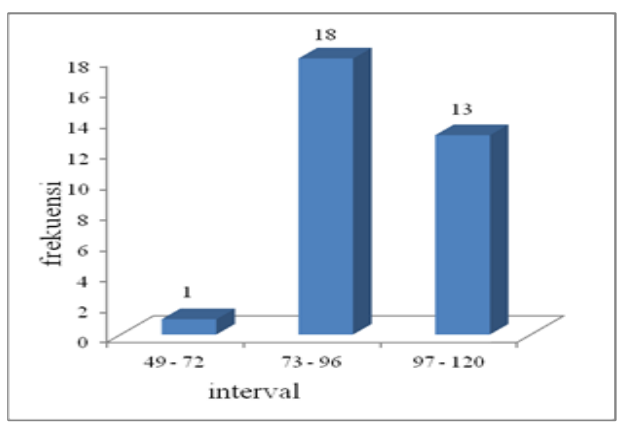

Gambar

3.

$$
\begin{array}{lr}
\text { Data } & \text { Kesiapan } \\
\text { Memasuki } & \text { Dunia } \\
\text { Kerja } &
\end{array}
$$

Berdasarkan gambar 3 bahwa

sebanyak 18 responden rata-rata menjawab setuju pada angket penelitian. Kemudian 13 responden rata-rata menjawab sangat setuju pada angket penelitian, dan terendah adalah sebanyak 1 responden menjawab ragu-ragu pada angket penelitian.

\section{Hasil Uji Persyaratan Analisis}

\section{a. Uji Normalitas}

Tabel 1.Uji Normalitas

\begin{tabular}{lccc}
\hline Variabel & $\begin{array}{l}\text { Nilai } \\
\text { Sign. }\end{array}$ & Kriteria & Kesimpulan \\
\hline $\begin{array}{l}\text { Praktik } \\
\text { kerja } \\
\text { lapangan }\end{array}$ & 0,186 & $>0,05$ & Normal \\
\hline $\begin{array}{l}\text { Prestasi } \\
\text { belajar }\end{array}$ & 0,166 & $>0,05$ & Normal \\
\hline $\begin{array}{l}\text { Kesiapan } \\
\text { memasuki } \\
\text { dunia } \\
\text { kerja }\end{array}$ & 0,066 & $>0,05$ & Normal \\
\hline
\end{tabular}

Melalui hail uji Normalitas menggunakan SPSS 20 dapat disimpulkan bahwa semua data yang dimiliki berdistribusi normal.

\section{b. Uji Linieritas}

Pada penelitian ini menggunakan uji test of linearity, melalui hasil perhitungan SPSS versi 20.

Tabel 2.Uji Linearitas X1 dan Y

\begin{tabular}{cccc}
\hline Variabel & $\begin{array}{c}\text { Nilai } \\
\text { Sign. }\end{array}$ & Kriteria & Kesimpulan \\
\hline $\mathrm{X}_{1}$ dan Y & 0,239 & $>0,05$ & $\begin{array}{c}\text { Hubungan } \\
\text { bersifat } \\
\text { linear }\end{array}$ \\
\hline
\end{tabular}

Melalui tabel diatas diketahui bahwa nilai signifikansi antara $X_{1}$ dan $\mathrm{Y}$ sebesar $0,239>0,05$ yang berarti terdapat hubungan yang linear antara pengalaman praktik kerja lapangan dengan kesiapan memasuki dunia kerja. 
Tabel 3.Uji Linearitas X2 dan Y

\begin{tabular}{cccc}
\hline Variabel & $\begin{array}{c}\text { Nilai } \\
\text { Sign. }\end{array}$ & Kriteria & Kesimpulan \\
\hline $\mathrm{X}_{2}$ dan Y & 0,167 & $>0,05$ & $\begin{array}{c}\text { Hubungan } \\
\text { bersifat } \\
\text { linear }\end{array}$ \\
\hline
\end{tabular}

Melalui tabel diatas diketahui bahwa nilai signifikansi antara $\mathrm{X}_{2}$ dan $\mathrm{Y}$ sebesar 0,167>0,05 yang berarti terdapat hubungan yang linear antara prestasi belajar dengan kesiapan memasuki dunia kerja.

\section{c. Uji Multikolinearitas}

Tabel 4.Uji Multikolinearitas

\begin{tabular}{cccc}
\hline Variabel & Tolerance & VIF & Kesimpulan \\
\hline X1 & 0,999 & 1,001 & $\begin{array}{c}\text { Bebas } \\
\text { Multikolinearitas }\end{array}$ \\
\hline X2 & 0,999 & 1,001 & $\begin{array}{c}\text { Bebas } \\
\text { Multikolinearitas }\end{array}$ \\
\hline
\end{tabular}

Melalui tabel diatas dapat diketahui bahwa nilai tolerance dari kedua variabel independen 0,999 > 0,10 . Kemudian nilai VIF semua variabel independen $1,001<10$, yang berarti tidak terjadi multikolinearitas.

\section{Hasil Uji Hipotesis}

Uji ini dilakukan untuk memprediksi apakah variabel pengalaman praktik kerja lapangan dan variabel prestasi belajar berpengaruh terhadap variabel kesiapan memasuki dunia kerja.
Tabel 5.Rangkuman Uji Hipotesis

\begin{tabular}{lccccc}
\hline Variabel & $\mathbf{B}$ & $\mathbf{R}^{2}$ & $\begin{array}{c}\mathbf{F} \\
\text { hitung }\end{array}$ & $\begin{array}{c}\mathbf{F} \\
\text { tabel }\end{array}$ & Sig. \\
\hline $\begin{array}{l}\text { Praktik } \\
\text { kerja } \\
\text { lapangan } \\
(\mathrm{x} 1)\end{array}$ & 0,546 & 0,645 & 26,341 & 3,32 & \\
\cline { 1 - 2 } $\begin{array}{l}\text { Prestasi } \\
\text { belajar } \\
(\mathrm{x} 2)\end{array}$ & 0,580 & & & & 0,000 \\
\cline { 1 - 2 } Konstanta & - & & & \\
\hline
\end{tabular}

Persamaan regresi sebagai berikut :

$Y=-17,913+0,546 X_{1}+0,580 X_{2}$

Dimana :

$\mathrm{Y}=$ nilai prediksi kesiapan memasuki dunia kerja

$-17,913=$ bilangan konstanta

$0,546 \mathrm{X}_{1}=$ koefisien pengalaman praktik kerja lapangan

$0,580 \mathrm{X}_{2}=$ koefisien prestasi belajar

Melalui hasil diatas, dapat diketahui bahwa $F_{\text {hitung }}=26,341$ sedangkan dari $F_{\text {tabel }}$ adalah 3,32. Sehingga $F_{\text {hitung }}>F_{\text {tabel }}$ dan nilai sig. $=0,000<0,05$. Jadi, Ha diterima yang berbunyi "ada pengaruh yang positif dan signifikan pengalaman praktik kerja lapangan dan prestasi belajar terhadap kesiapan memasuki dunia kerja". Dari hasil persamaan regresi ganda dapat digunakan untuk melakukan prediksi. Hal ini berarti pengalaman praktik kerja lapangan 
dan prestasi belajar secara bersamasama dapat digunakan untuk melakukan prediksi terhadap kesiapan memasuki dunia kerja.

Hasil persamaan regresi ganda secara rinci memiliki makna :

1) Bilangan konstanta sebesar 17,913, artinya jika praktik kerja lapangan dan prestasi belajar nilainya adalah 0 , maka kesiapan memasuki dunia kerja nilainya sebesar -17,913.

2) Koefisien regresi variabel praktik kerja lapangan bernilai positif sebesar 0,546, artinya jika variabel pengalaman praktik kerja lapangan mengalami kenaikan 1 poin maka kesiapan memasuki dunia kerja akan mengalami peningkatan sebesar 0,546 , dengan asumsi variabel prestasi belajar nilainya tetap.

3) Koefisien regresi variabel prestasi belajar bernilai positif sebesar 0,580, artinya jika variabel prestasi belajar mengalami kenaikan 1 poin maka kesiapan memasuki dunia kerja akan mengalami peningkatan sebesar 0,580, dengan asumsi variabel pengalaman praktik kerja lapangan nilainya tetap.

Hasil perhitungan menunjukan nilai koefisien determinasi $\left(\mathrm{R}^{2}\right)$ sebesar 0,645. Artinya besarnya pengaruh pengalaman praktik kerja lapangan dan prestasi belajar terhadap kesiapan memasuki dunia kerja sebesar 64,5\%, dan sisanya dipengaruhi oleh variabel lain yang tidak diteliti dalam penelitian ini.

\section{Sumbangan Efektif dan Relatif}

Tabel 6. Hasil Perhitungan Sumbangan Efektif dan Relatif

\begin{tabular}{ccc}
\hline \multirow{2}{*}{ Variabel } & \multicolumn{2}{c}{ Sumbangan } \\
\cline { 2 - 3 } & Efektif $(\%)$ & Relatif (\%) \\
\hline $\mathrm{X} 1$ & $61.146 \%$ & $94.80 \%$ \\
\hline $\mathrm{X} 2$ & $3.354 \%$ & $5.20 \%$ \\
\hline Total & $64.50 \%$ & $100.00 \%$ \\
\hline
\end{tabular}

\section{PEMBAHASAN}

1. Pengaruh Praktik Kerja Lapangan dengan Kesiapan

\section{Memasuki Dunia Kerja}

Hasil uji hipotesis dengan menggunakan analisis regresi sederhana mendapatkan hasil koefisien regresi X1 sebesar 0,549, koefisien regresi tersebut bernilai 
positif, nilai signifikansi sebesar $0,000<0,05$, dan nilai $t_{\text {hitung }}$ sebesar $6,913>t_{\text {tabel }} 2,045$. Sehingga dapat disimpulkan terdapat pengaruh yang positif dan signifikan pengalaman praktik kerja lapangan terhadap kesiapan memasuki dunia kerja. Artinya semakin banyak pengalaman yang diperoleh siswa pada saat praktik kerja lapangan, maka kesiapan memasuki dunia kerja siswa semakin tinggi pula. Sebaliknya semakin sedikit pengalaman yang diperoleh siswa pada saat praktik kerja lapangan, maka kesiapan memasuki dunia kerja siswa semakin rendah.

\section{Pengaruh Prestasi Belajar dengan Kesiapan Memasuki Dunia Kerja}

Berdasarkan hasil uji hipotesis yang kedua dengan analisis regresi sederhana mendapatkan hasil koefisien regresi X2 sebesar 0,640, koefisien regresi tersebut bernilai positif, nilai signifikansi sebesar $0,290>0,05$, dan nilai $t_{\text {hitung }}$ sebesar $1,078<\mathrm{t}_{\text {tabel }} 2,045$. Sehingga dapat disimpulkan bahwa variabel prestasi belajar tidak terdapat pengaruh yang signifikan terhadap kesiapan memasuki dunia kerja. Sehingga apabila prestasi belajar tinggi, belum tentu kesiapan memasuki dunia kerja juga tinggi. Hipotesis kedua ini menolak Ha sebagai hipotesis kerja.

3. Pengaruh Praktik Kerja Lapangan dan Prestasi Belajar dengan Kesiapan Memasuki Dunia Kerja

Berdasarkan hasil uji hipotesis yang ketiga dengan analisis regresi ganda mendapatkan nilai $F_{\text {hitung }}=26,341$ sedangkan dari $F_{\text {tabel }}$ adalah 3,32. Sehingga $F_{\text {hitung }}>F_{\text {tabel }}$ dan nilai sig. $=0,000<0,05$. Jadi dapat dibuktikan bahwa variabel pengalaman praktik kerja lapangan dan variabel prestasi belajar secara bersama-sama berpengaruh positif dan signifikan terhadap kesiapan memasuki dunia kerja. Artinya apabila pengalaman praktik kerja lapangan dan prestasi belajar tinggi atau meningkat secara bersamaan, maka kesiapan memasuki dunia kerja juga akan meningkat.

\section{SIMPULAN}

1. Ada pengaruh yang positif dan signifikan antara praktik kerja lapangan dengan kesiapan 
memasuki dunia kerja pada siswa kelas XI TGB. Hal ini terbukti dari hasil analisi regresi sederhana yang memperoleh hasil $t_{\text {hitung }}$ sebesar 6,913 > $\mathrm{t}_{\text {tabel }} 2,045$ pada taraf signifikansi $5 \%$.

2. Tidak terdapat pengaruh yang signifikan variabel prestasi belajar terhadap kesiapan memasuki dunia kerja pada siswa kelas XI TGB. Sehingga apabila prestasi belajar tinggi, belum tentu kesiapan memasuki dunia kerja juga tinggi. Hal ini dilihat dari hasil analisi regresi sederhana yang memperoleh hasil $t_{\text {hitung }}$ sebesar $1,078<\mathrm{t}_{\text {tabel }} 2,045$ pada taraf signifikansi $5 \%$.

3. Ada pengaruh yang positif dan signifikan antara praktik kerja lapangan dan prestasi belajar dengan kesiapan memasuki dunia kerja pada siswa kelas XI TGB. Hal ini terbukti dari hasil analisi regresi ganda yang memperoleh hasil $F_{\text {hitung }}=26,341$ sedangkan dari $F_{\text {tabel }}$ adalah 3,32. Sehingga $\mathrm{F}_{\text {hitung }}>\mathrm{F}_{\text {tabel }}$ dan nilai sig. $=0,000$ $<0,05$ pada taraf signifikan $5 \%$.

\section{SARAN}

1. Siswa diharapkan memanfaatkan waktu sebaik - baiknya saat mengikuti pembelajaran dan praktik kerja lapangan agar mendapatkan ilmu yang maksimal.

2. Guru pembimbing PKL diharapkan rajin menevaluasi dan monitoting siswa saat pelaksanaan PKL.

3. Untuk sekolah, khususnya jurusan teknik sipil diharapkan terus meningkatkan dan memperbaiki kegiatan praktik kerja lapangan, agar selama kegiatan praktik kerja lapangan siswa tidak membolos dan sering izin.

4. Untuk sekolah, khususnya SMK diharapkan lebih giat dalam meningkatkan kualitas lulusannya.

5. Hendaknya dilakukan penelitian lanjutan terhadap kesiapan memasuki dunia kerja dengan variabel - variabel lain yang lebih berhubungan. 


\section{DAFTAR PUSTAKA}

Djojonegoro, W. (1998). Pengembangan Sumberdaya Manusia Melalui Sekolah Menengah Kejuruan (SMK). Jakarta: PT Jayakarta Agung Offset.

Fitriyanto, A.( 2006). Ketidak Siapan Memasuki Dunia Kerja Karena Pendidikan. Jakarta : Dinamika Cipta.

Hamalik, O. (2007). Pengembangan SDM Manajemen Pelatihan Ketenagakerjan Pendekatan Terpadu. Jakarta: Bumi Aksara.

Mipalas, Y. \& Taman, A. (2012). Pengaruh Pengalaman Praktik Industri Dan Prestasi Belajar Terhadap Kesiapan Kerja Siswa Kelas XI Program Keahlian Akuntansi SMK YPKK2 Sleman Yogyakarta, Jurnal Kajian Pendidikan Akuntansi Indonesia, 161-183.

Muktiani, E.E. (2013). Pengaruh Praktik Kerja Industri Dan Prestasi Akademik Mata Diklat Produktif Akuntansi Terhadap Kesiapan Kerja Siswa Kelas XI Program Keahlian Akuntansi SMK Nasional Pati Tahun Pelajaran 2012/2013. Economic Education Analysis Journal . Universitas Negeri Semarang.

Slameto. (2010). Belajar dan Faktor-Faktor Yang Mempengaruhinya. Jakarta : Rineka Cipta.

Sudjana.(2009). Penilaian Hasil Proses Belajar Mengajar. Bandung : PT Remaja Rosadakarya.

Tirtonegoro, S.( 2001). Anak Super Bormal Dan Program Pendidikannya. Jakarta : Bumi Aksara. 